\title{
Seroprevalence and pathology of naturally infected Salmonellosis in poultry with isolation and identification of causal agents
}

\author{
A.K.M. Ahmed, M.T. Islam, M.G. Haider and M.M. Hossain \\ Department of Pathology, Bangladesh Agricultural University, Mymensingh-2202, Bangladesh
}

\begin{abstract}
The present study was conducted to determine the seroprevalence of Salmonella infections in poultry. This study covered cultural prevalence with isolation and identification of the causal agent and pathological lesions in different organs produced by Salmonella in layer farms of Mymensingh district during July-December 2007. The materials were blood samples, liver and cloacal swabs from live and dead birds. The used methods were whole blood agglutination test by commercially available Salmonella antigen kit, culture in different media, Gram's staining, motility test, basic 5 sugar fermentation test and histopathology. The overall seroprevalence was $45.9 \%$ in live bird and the rate of seroprevalence decreased with advancement of age of birds. The cultural prevalence in seropositive group was $71 \%$ and in seronegative group was 59\%. In dead bird, the cultural prevalence in liver was $64 \%$ and from cloaca 57\%. A total 160 isolates were characterized, among them $64.2 \%$ were Salmonella Pullorum, 22.3\% were Salmonella Gallinarum and $13.5 \%$ were Paratyphoid group of Salmonellae. Pathologically friable, bronze color liver with focal necrosis, various grades of enteritis, and hemorrhagic and congested egg follicles with stalk formation were found. Microscopically, focal necrosis and degeneration with leukocytic infiltration in liver, inflammatory cells in the mucosa and submucosa of intestine were found. In egg follicles, congestion and hemorrhages with leukocytic infiltration were found. The isolated Salmonella organisms may be used for further research such as serotyping, vaccine production and antibiotic sensitivity test.
\end{abstract}

Keywords: Salmonellosis, Seroprevalence, Agglutination test, Histopathology, Poultry

\section{Introduction}

There are several constraints in the development of poultry industry in Bangladesh (Das et al., 2005). Infections with bacteria of the genus Salmonella are responsible for major problem of poultry farming in Bangladesh (Kamaruddin and Giasuddin, 2003). In recent days, the prevalence of Salmonellosis in both breeder flock, commercial broiler and layer flocks is increasing day by day. For the control and proper treatment of Salmonellosis in a particular commercial poultry farm, the Salmonellosis status of that commercial farm should be determined considering age, sex, breed of poultry and management of the farm. Keeping this in consideration this study was undertaken.

\section{Materials and Methods}

The study was conducted during the period from July to December 2007, at Krishibid farm under Thrishal Upazilla of Mymensingh district. There were 10 layer flocks containing 60,582 birds where there was no history of using Salmonellla vaccine.

\section{Seroprevalence study}

Collection of blood: At the rate of $0.8 \%$ (conventional method of seroprevalence determination practice), 481 birds were tested randomly from 60,582 birds. $3 \mathrm{ml}$ sterile disposable syringe and needle was used and blood was aseptically collected from the wing veins. During this period, the birds were classified into group according to their age as starter (0-8 wks), grower (8-20 wks), and layer (20 wks onward) (Table1). 


\section{Whole blood agglutination (WBA) test}

Whole blood agglutination test was preformed according to the instruction of OIE (2004). To perform the test, $0.02 \mathrm{ml}$ of blood was rapidly placed into the glass slide and $0.02 \mathrm{ml}$ of Salmonella color antigen (Nobillis ${ }^{\circledR}$ SP antigen, Intervet, Holland) was poured on the blood and mixed thoroughly by using tooth picks followed by rocking. Grading of positive case as ,,++++++ (Figs. $2 \& 3$ ) was done on the basis of granule formation. In negative case, no such granules were found within 2 minutes. Granules found after 2 minutes was considered as negative.

\section{Cultural prevalence study with isolation and identification of Salmonella organism}

Sample collection: Total 192 cloacal swabs from live bird in which 96 from seropositive and 96 from seronegative birds were collected from the same flock at the same time of seroprevalence study. Postmortem examinations of 28 dead birds were performed and 28 liver and 28 cloacal swabs of dead birds were also collected from the flock throughout the experimental period.

Cultural media: After overnight incubation in TTB, all the samples were subcultured in the Salmonella-Shigella (SS) agar, Triple sugar iron (TSI) agar, Brilliant green agar (BGA), Blood agar (BA), Eosine methylene blue (EMB) agar.

Morphological characterization: The presumptive colonies of Salmonella in different media were characterized microscopically using Gram's stain (Merchant and Packer, 1967).

Carbohydrate fermentation test and biochemical test: Five basic sugars such as glucose, sucrose, lactose, mannitol and maltose were used for sugar fermentation test. Biochemical test included MR test, VP test, Indole test and dulcitol fermentation test.

Motility test: For separation of motile and non-motile Salmonellae motility test was done according to Cown (1985).

\section{Pathological studies}

During the whole period of seroprevalence study in the representative flock, necropsy of dead bird was done routinely. Gross pathological changes at necropsy were carefully observed and recorded and tissue samples were preserved in 10\% neutral buffered formalin for histopathological studies. For histopathological studies the tissues were trimmed, washed in water, dehydration in alcohol, cleaning in chloroform, blocking in paraffin and sectioned with microtome. The sections were stained with routine hematoxylin and eosin staining (Luna, 1968) and finally the section were studied with light microscope.

\section{Results and Discussion}

\section{Seroprevalence study}

In this study, the overall seroprevalence of Salmonella infection in chicken was $45.9 \%$ which was supported by Arsenault et al. (2007), Islam et al. (2006). However, Jai-Sundar et al. (2007), Habib-ur-Rehman et al. (2003), Ashenafi et al. (2003) and Hoop and Pospischil (1993) reported $61.68 \%, 63.5 \%, 64.2 \%$ and $64.9 \%$ seroprevalence, respectively which were higher than the present findings. The variation might be due to the differences in environmental, managemental and geographical distribution. Mdegela et al. (2000) reported $2.6 \%$, Robinson et al. (2000) reported 18.4\%, Jha et al. (1995) reported $21.3 \%$ and $12 \%$ seroprevalence in two village flock which was much lower than the present study. This might be due to as all the prevalence study was taken from village chickens where the prevalence of Salmonella infection was generally lower than the commercial chickens (Mdegela et al., 2000; Robinson et al., 2000) (Table 1). 
Ahmed et al.

Table 1. Seroprevalence of Salmonella infection in chicken of different age groups and flocks

\begin{tabular}{|c|c|c|c|c|c|c|c|c|c|}
\hline \multirow{2}{*}{$\begin{array}{l}\text { Flock } \\
\text { Type }\end{array}$} & \multirow{2}{*}{$\begin{array}{l}\text { Flock } \\
\text { No. }\end{array}$} & \multirow{2}{*}{$\begin{array}{l}\text { Age } \\
\text { (day) }\end{array}$} & \multirow{2}{*}{$\begin{array}{c}\text { No. of } \\
\text { blood test }\end{array}$} & \multicolumn{4}{|c|}{ Seropositive } & \multirow{2}{*}{$\begin{array}{c}\text { Prevalence } \\
\%\end{array}$} & \multirow{2}{*}{$\begin{array}{c}\text { Flock } \\
\text { Sero-Prevalence } \\
\%\end{array}$} \\
\hline & & & & +++ & ++ & + & Total & & \\
\hline \multirow{2}{*}{ Starter } & $\mathrm{F}-20$ & 6 & 97 & 13 & 13 & 41 & 67 & 69 & \multirow{2}{*}{63.4} \\
\hline & F-19 & 52 & 48 & 5 & 8 & 12 & 25 & 52 & \\
\hline Grower & F-18 & 112 & 48 & 3 & 7 & 17 & 27 & 56 & 56.2 \\
\hline \multirow{7}{*}{ Layer } & $\mathrm{F}-17$ & 157 & 40 & 1 & 4 & 11 & 16 & 40 & \multirow{7}{*}{35.4} \\
\hline & F-16 & 196 & 48 & - & 5 & 14 & 19 & 39 & \\
\hline & F-15 & 201 & 52 & - & 4 & 16 & 20 & 38 & \\
\hline & $\mathrm{F}-14$ & 247 & 54 & 1 & 3 & 13 & 17 & 31 & \\
\hline & $\mathrm{F}-13$ & 266 & 40 & - & - & 12 & 12 & 30 & \\
\hline & $\mathrm{F}-12$ & 320 & 22 & - & - & 6 & 6 & 27 & \\
\hline & $\mathrm{F}-10$ & 543 & 32 & - & - & 12 & 12 & 37 & \\
\hline Total & & & 481 & & & & 221 & & 45.9 \\
\hline
\end{tabular}

$\mathrm{F}=$ Flock

Within the different age groups, starter showed the maximum seroprevalence of $63.4 \%$, grower $56.2 \%$ and layer $35.4 \%$. Among the different flocks, 6 days old chicks (F-20) showed the maximum $69 \%$ seroprevalence and F-19, F-18, F-17, F-16, F-15, F-14, F-13, F-12 and F-10 showed 52\%, 56\%, 40\%, 39\%, 38\%, 31\%, 30\%, 27\% and 37\% seroprevalence, respectively. 320 days old layer (F-12) showed the minimum $27 \%$ of seroprevalence. In the present study, the highest seroprevalence was observed in the starter group (63.4\%) and lowest in the layer group (35.4\%). Within the different aged flocks, one of the flocks showed the maximum $69 \%$ at the age of 6 days. The seroprevalence $\%$ declined with the advancement of age in the present study (Fig. 1). However, Islam et al., (2006) found increased rate of seroprevalence with the advancement of age. In this study the increase rate of seroprevalence in young age may be due to 1). Infection received from parent stock through vertical transmission 2). Infection received from environment i.e. horizontal transmission. The decrease rate of seroprevalence with the advancement of age may be due to the continuous antibiotic treatment from day old chicks and upto post laying period.

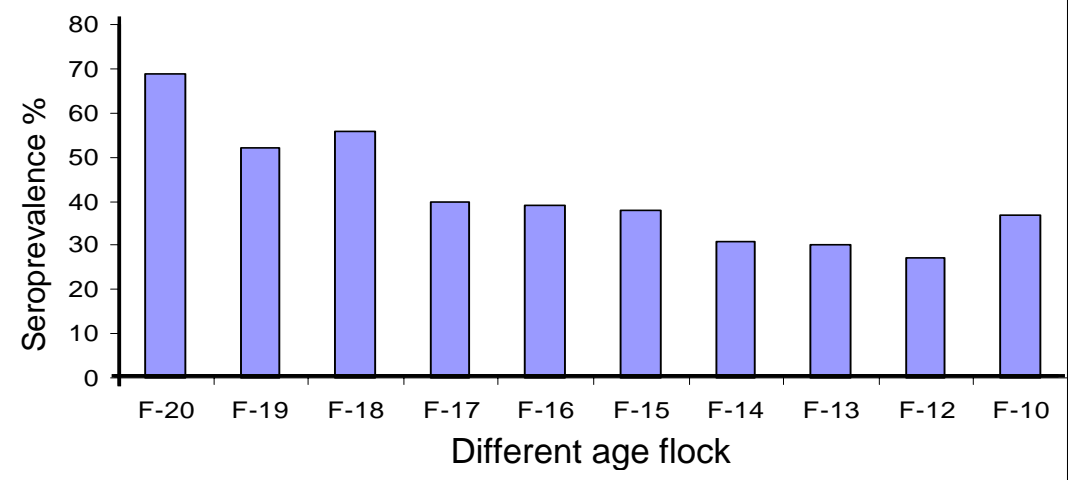

Fig. 1. Variation in seroprevalence in different age flocks 
In another two flocks with 112 and 543 days showed slightly higher seroprevalence $56 \%$ and $37 \%$, irrespective to age. This might be due to the repeated infection of Salmonella organisms in that flocks.

\section{Cultural prevalence with isolation and identification of Salmonella organism}

Isolation and cultural character of Salmonella in different media: Isolated Salmonella organisms showed different cultural characteristics in different media. These were turbidity in TTB, pink white color colonies in BGA, whitish or slightly grayish color colonies in SS agar, black color colony in TSI agar, pale color colonies in Mac Conkey's agar, well defined glistening colonies in blood agar and pinkish colonies in EMB agar (Rybolt et al., 2005; Perez et al., 2004).

Morphological characterization: From pure culture of different media, Gram's staining was performed to observe Salmonella organism. Under compound light microscope the organism was identified as Gram-negative, rod shaped and arranged in single. Chains of more than two bacilli were normally absent (Freeman, 1985; Khan et al., 1998).

Carbohydrate fermentation tests and biochemical tests: Different biochemical tests were used for identification of Salmonella organism in this study. All Salmonella were MR positive and VP and indole negative. In the dulcitol fermentation test, Salmonella Pullorum and Salmonella Gallinarum was dulcitol non-fermenter but paratyphoid causing Salmonellae fermented dulcitol (Haider et al., 2003;; Buxton and Fraser, 1977; Merchant and Packer, 1967). Different carbohydrate fermentation tests were used to differentiate the isolates. All Salmonella isolates were lactose and sucrose negative but fermented glucose and mannitol with acid and gas production. Salmonella Pullorum did not ferment maltose while others fermented maltose (Sujatha et al., 2003; Haider et al., 2003) (Table 2)

Table 2. Carbohydrate fermentation tests and biochemical tests of isolated Salmonella from live and dead bird

\begin{tabular}{|c|c|c|c|c|c|c|c|c|c|c|c|c|}
\hline SL\# & Lac & Suc & Mal & Glu & Man & Dul & MR & VP & Ind & Motility & Isolates & $\begin{array}{c}\text { No. of } \\
\text { isolates }\end{array}$ \\
\hline 1 & - & - & - & A/AG & AG & - & + & - & - & - & S. Pullorum & 103 \\
\hline 2 & - & - & A & A & A & + & + & - & - & - & S. Gallinarum & 35 \\
\hline 3 & - & - & AG & AG & AG & + & + & - & - & + & $\begin{array}{c}\text { Paratyphoid } \\
\text { causing } \\
\text { Salmonellae }\end{array}$ & 22 \\
\hline
\end{tabular}

Lac $=$ Lactose, Suc $=$ Sucrose, Mal $=$ Maltose, Glu $=$ Glucose, Man $=$ Mannitol, Dul=Dulcitol, MR $=$ Methyl Red, VP= Voges Proskauer, Ind= Indole, $A=A c i d, A G=$ Acid and Gas.

Motility test: 138 Salmonella isolates were identified as non-motile and 22 Salmonella were identified as motile (Buxton and Fraser, 1977; Islam et al., 2006)

\section{Cultural prevalence of Salmonella isolated from live birds}

The cultural prevalence from cloacal swabs was $71 \%$ in seropositive birds and $59 \%$ in seronegative birds. From these findings it might be speculated that the presence or absence of antibody in the blood were not directly related with the presence of bacteria in the digestive tract. In seropositive birds, there was a higher cultural prevalence (71\%) than the seronegative birds which might be due to repeated exposure of Salmonella infection and 
continuous antibiotic treatment in all ages of birds. Similar result was described by Truong and Tieuquang, (2003) where they obtained upto $66 \%$ of Salmonella in seropositive group but they did not explained the mechanism why the isolation rate in seropositive group was higher. In seronegative group, Salmonella was also recovered at a prevalence rate of 59\%. This might be assumed that after Salmonella infection, time did not elapse for antibody production (Table 3).

Table 3 Cultural prevalence of Salmonella isolated from live birds

\begin{tabular}{|c|c|c|c|c|c|}
\hline \multicolumn{2}{|l|}{ Seropositive group } & \multicolumn{3}{|l|}{ Seronegative group } \\
\hline $\begin{array}{c}\text { Cloacal swab } \\
\text { tested }\end{array}$ & $\begin{array}{c}\text { Positive } \\
\text { in culture }\end{array}$ & $\begin{array}{c}\text { Cultural } \\
\text { prevalence \% }\end{array}$ & $\begin{array}{c}\text { Cloacal swab } \\
\text { tested }\end{array}$ & $\begin{array}{c}\text { Positive in } \\
\text { culture }\end{array}$ & $\begin{array}{c}\text { Cultural } \\
\text { prevalence\% }\end{array}$ \\
\hline 96 & 69 & 71 & 96 & 57 & 59 \\
\hline
\end{tabular}

\section{Cultural prevalence of Salmonella isolated from dead bird}

The average cultural prevalence in the dead bird was $60.5 \%$ in which $64 \%$ cultural prevalence in the liver and $57 \%$ in the cloaca (Table 4). Habib-ur-Rehman et al. (2003) described $34.5 \%$ cultural prevalence of Salmonella infection in liver while Lee et al. (2001) described $47.6 \%$.

Table 4 Cultural prevalence of Salmonella isolated from dead bird

\begin{tabular}{|c|c|c|c|c|c|c|}
\hline \multicolumn{3}{|c|}{ Liver } & \multicolumn{3}{|c|}{ Cloaca } & \multirow[b]{2}{*}{$\begin{array}{c}\text { Average } \\
\text { Prevalence } \\
\%\end{array}$} \\
\hline Swab tested & $\begin{array}{l}\text { Positive } \\
\text { in culture }\end{array}$ & $\begin{array}{c}\text { Cultural } \\
\text { prevalence \% }\end{array}$ & $\begin{array}{l}\text { Swab } \\
\text { tested }\end{array}$ & $\begin{array}{l}\text { Positive in } \\
\text { culture }\end{array}$ & $\begin{array}{c}\text { Cultural } \\
\text { prevalence } \\
\%\end{array}$ & \\
\hline 28 & 18 & 64 & 28 & 16 & 57 & 60.5 \\
\hline
\end{tabular}

In the present study, the higher prevalence of Salmonella in dead bird may be due to the case fatality. Similar findings were supported by other investigators (Tibaijuka et al., 2003; Lee et al., 2001).

\section{Distribution of Salmonella from live and dead birds}

Among the 160 isolates, $64.2 \%$ (103) was identified as Salmonella Pullorum, 22.3\% (35) Salmonella Gallinarum and 13.5\% (22) paratyphoid causing Salmonellae (table 5). This result was similar to Islam et al. (2006) with a small variation which might be due to the difference in managemental condition (Table 5).

Table 5. Isolation and distribution of Salmonella from live and dead birds

\begin{tabular}{|l|c|c|c|c|c|c|c|c|}
\hline $\begin{array}{l}\text { Source of } \\
\text { Samples }\end{array}$ & $\begin{array}{c}\text { No. of } \\
\text { sample }\end{array}$ & Total & $\begin{array}{c}\text { No. of } \\
\text { Isolates }\end{array}$ & $\begin{array}{c}\text { Prevalence } \\
\%\end{array}$ & $\begin{array}{c}\text { Total } \\
\text { isolates }\end{array}$ & Distribution & Species & $\begin{array}{c}\text { Percentage } \\
\%\end{array}$ \\
\hline Live bird & 192 & & 126 & 65 & & 103 & S. Pullorum & 64.2 \\
\cline { 7 - 9 } & & \multirow{2}{*}{248} & 34 & 60.5 & 160 & 35 & S. Gallinarum & 22.3 \\
\cline { 6 - 9 } & Dead bird & 56 & & & & 22 & $\begin{array}{c}\text { Paratyphoid } \\
\text { causing } \\
\text { Salmonellae }\end{array}$ & 13.5 \\
\hline
\end{tabular}




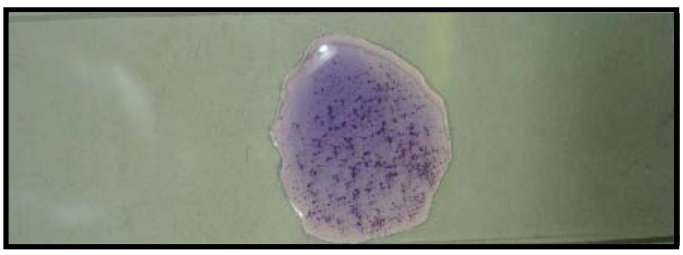

Fig. 2. Shows the positive reaction (+++) of Salmonella antigen (Nobilis ${ }^{\circledR} \mathrm{SP}$ ) with whole blood of chickens

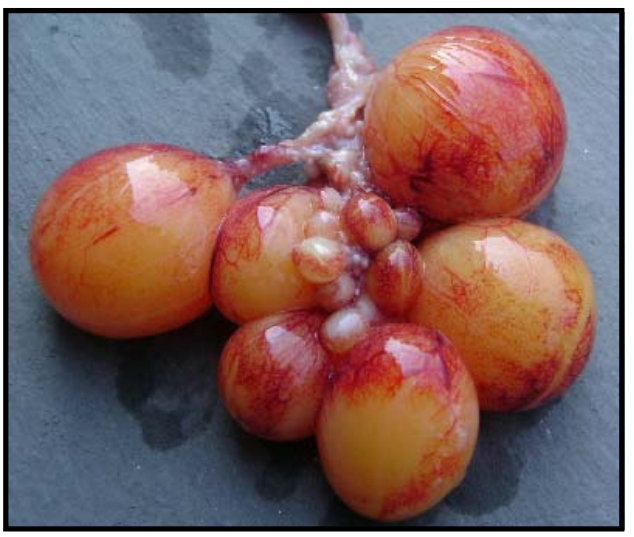

Fig. 4. Salmonella affected ovarian follicles of chicken shows congestion, discoloration and stalk formation

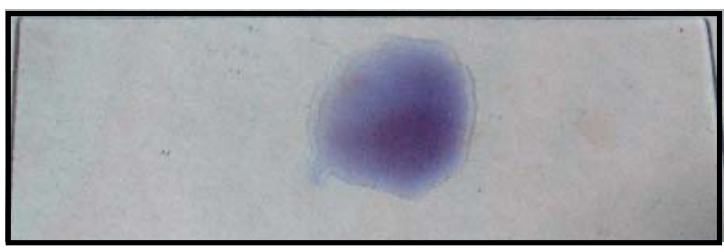

Fig. 3. Shows the negative (-) reaction of Salmonella antigen (Nobilis ${ }^{\circledR}$ SP) with whole blood of chickens

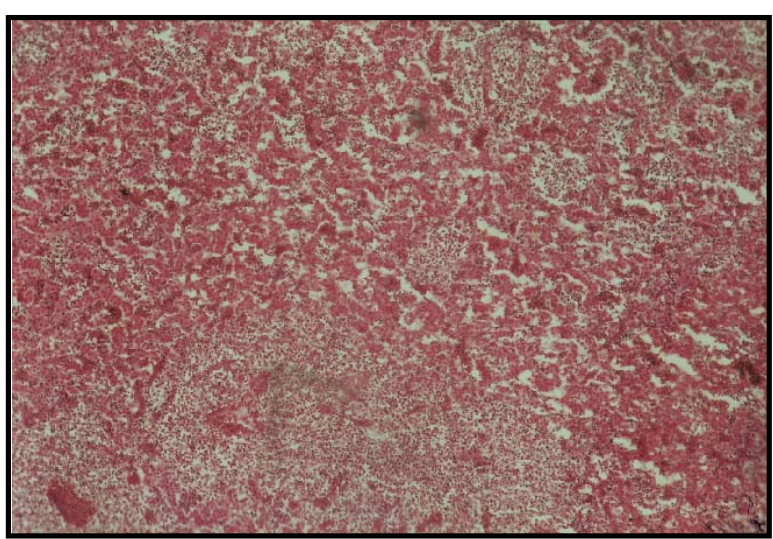

Fig. 5. Salmonella infected liver shows hemorrhages, focal degeneration and necrosis (H\&E staining 83X)

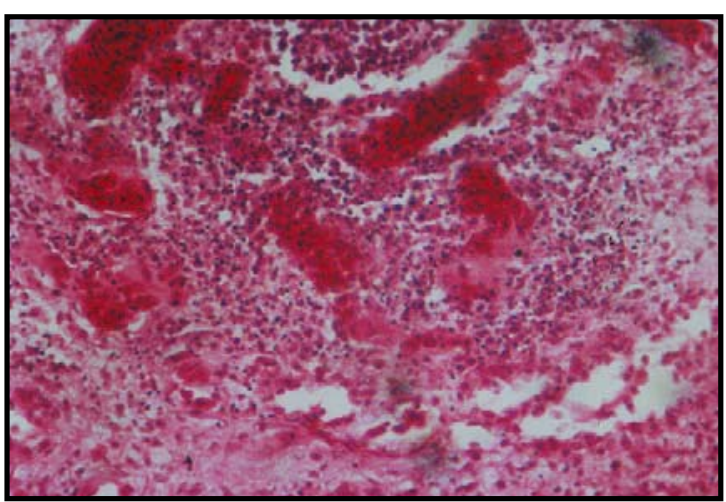

Fig. 6. Salmonella infected lungs shows inflammatory cells in the alveoli and bronchus that causes bronchopneumonia (H\&E staining $330 \mathrm{X}$ )

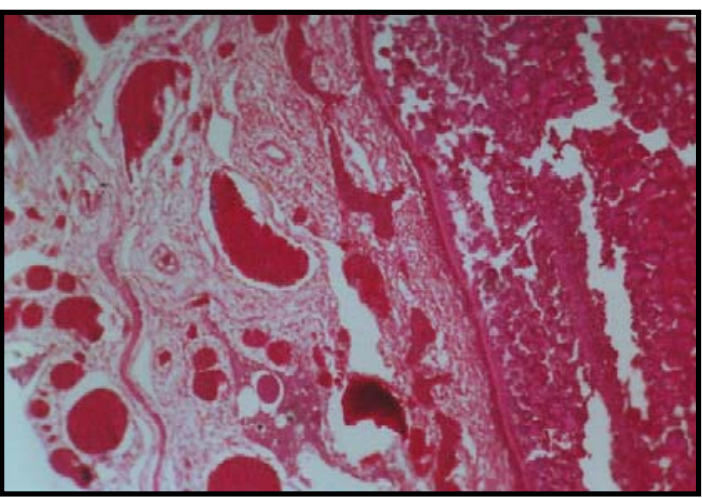

Fig. 7. Salmonella affected egg follicles shows marked congestion and leukocytic infiltration in the egg yolk (H\&E staining 83X) 


\section{Pathological studies}

The gross lesions in the liver showed variable changes including friable and bronze discoloration with white necrotic foci. Lungs were congested and pneumonic. Spleen was enlarged with discoloration. Intestine showed various grades of enteritis with mucous in the lumen. Ovary showed hemorrhagic lesions including stalk formation or pedunculated eggs (Fig. 4). Degenerated and discolored eggs were found. Yolk sac with hemorrhage and congestion was observed. These findings were supported by Deshmukh et al. (2007); Msoffe et al. (2006); Islam et al. (2006); Calnek et al., (1991). Microscopically liver showed congestion, hemorrhages, focal degeneration and necrosis (Fig. 5). There was accumulation of leukocytes which replaced the degenerated or necrotic liver cells. In intestine there were inflammatory cells in the mucosa and submucosa, and the infiltrated reactive cells were heterophils and lymphocytes. Salmonella affected lungs of chickens showed pneumonia and congestion (Fig. 6). Egg follicles showed marked congestion with leukocytic infiltration in the yolk (Fig.7). Yolk sacs showed infiltration of leukocytes and marked congestion. The microscopic lesions recorded in the present investigation were almost similar to the lesions described by Deshmukh et al. (2007); Holt et al. (2006); Msoffe et al. (2006); Khan et al. (1998); and Calnek et al. (1991).

From the above discussion, it may be concluded that seroprevalence study is the way of choice of Salmonella antibody determination in serum. But the presence or absence of antibody in the blood is not directly related with the presence or absence of organisms in the digestive tract. Repeated exposure of Salmonella infection and time elapsed for antibody productions are also the factors for serological presence or absence of Salmonella antibody. In the present study, seroprevalence, cultural prevalence and pathology of Salmonella affected organs have been studied well. However further studies with serotyping, vaccine production and antibiotic sensitivity determination with locally isolated Salmonellae from poultry should be elucidated in future.

\section{References}

Arsenault, J., Letellier, A., Quessy, S., Normand, V. and Boulianne, M. 2007. Prevalence and risk factors for Salmonella spp. and Campylobacter spp. caecal colonization in broiler chicken and turkey flocks slaughtered in Quebec, Canada. Prev. Vet. Med. 81:250-64.

Ashenafi, H., Shetu, Y. and Oldemeskel, M. 2003. Identification of major infections of local chickens of Central Ethiopia. Bull. Ani. Heal. Pro. Africa. 51:95-101.

Buxton, A. and Fraser, G. 1977. Animal Microbiology. Vol. 1. Blackwell Scientific Publications, Oxford, London, Edinburgh, Melbourne. 103-115.

Calnek, B.W., Barnes, H.J., Beard, C.W., Mcdougald, L.R. and Saif, Y.M. 1991. Diseases of Poultry. $10^{\text {th }}$ edn. Iowa State University Press, Ames, USA. 81-130.

Cown, S.T. 1985. Cown and Steel's Manual for the Identification of Medical Bacteria. $2^{\text {nd }}$ ed. Cambridge University Press, Cambridge, UK.

Das, P.M., Rajib, D.M.M., Noor, M. and Islam, M.R. 2005. Retrospective analysis on the proportional incidence of poultry diseases in greater Mymensingh district of Bangladesh. In proceeding of $4^{\text {th }}$ International Poultry Show \& Seminar, from February 28 to March 2, 2003, held in Bangladesh China Friendship Conference Centre, Agargaon, Dhaka. 35-39.

Deshmukh, S., Asrani, R.K., Ledoux, D.R., Rottinghaus, G.E., Bermudez, A.J. and Gupta, V.K. 2007. Pathologic changes in extrahepatic organs and agglutinin response to Salmonella Gallinarum infection in Japanese quail fed Fusarium verticillioides culture material containing known levels of fumonisin B1. Avian Dis. 51: 705-12.

Freeman, B.A. 1985. Burrow's Text Book of Microbiology. $22^{\text {nd }}$ ed. W. R. Saunders Company, London, UK. 372-472.

Habib-ur-Rehman, S., Sirzanin, Hamayun, K., Saleem, K., Nazir, A. and Bhatti, W.M. 2003. Incidence and gross pathology of Salmonellosis in chicken in Hyderabad. J. Asso. Vet. Advances. 2: 581-584. 
Haider, M.G., Hossain, M.G., Hossain, M.S., Chowdhury, E.H., Das, P.M. and Hossain, M.M. 2003. Isolation and characterization of enterobacteria associated with health and disease in Sonali chickens. Bang. J. Vet. Med. 2: 15-21.

Holt, P.S., Vaughn, L.E., Moore, R.W. and Gast, R.K. 2006. Comparison of Salmonella enterica serovar Enteritidis levels in crops of fed or fasted infected hens. Avian Dis. 50: 425-9.

Hoop, R.K. and Pospischil A. 1993. Bacteriological, serological, histological and immunohistochemical findings in laying hens with naturally acquired Salmonella Enteritidis phage type 4 infections. Vet. Rec. 133: 391-3.

Islam, M.M., Hossain, M.M., Haider, M.G., Chowdhury, E.H. and Kamruzzaman, M. 2006. Seroprevalence and pathological study of Salmonella infections in layer chickens and isolation of causal agents: In Proceedings of the $5^{\text {th }}$ International Poultry show and seminar from 01-03 march 2007, held in Bangladesh China Friendship Conference Centre (BCFCC), Sher-e-Bangla Nagar, Dhaka, Bangladesh. 9-15.

Jai-Sundar, Rai. R.B., Kundu, A., Senani, S., Chatterjee, R.N. and Jeyakumar, S. 2007. Seroprevalence of poultry diseases in Andaman and Nicobar Islands. Indian Vet. J. 84: 95-96.

Jha, V.C., Thakur, R.P., Chand, T.K. and Yadav, J.N. 1995. Prevalence of Salmonellosis in chickens in the Eastern Nepal. Vet. Bull. 65: 7.

Kamaruddin, K.M. and Giasuddin, M. 2003. Poultry disease and its diagnostic facilities. Growth of poultry industry in Bangladesh with poverty alleviation and employment opportunity. In Proceedings of $3^{\text {rd }}$ International poultry show and seminar, from February 28 to March 2, 2003, held in Bangladesh China Friendship Conference Center (BCFCC) at Sher-e-Bangla Nagar, Dhaka, Bangladesh. 141-148.

Khan, A.H.M.N.A., Bari, A.S.M., Islam, M.R., Das, P.M. and Ali, M.Y. 1998. Pullorum disease in semi mature chickens and its experimental pathology. Bang. Vet. J. 32: 124-128.

Lee, Y.J., Kang, M.S., Woo, Y.K., Mo, I.P. and Tak, R.B. 2001. Competitive exclusion against S. Gallinarum of S. Enteritidis infected chickens. J. Vet. Sci. 2: 33-36.

Luna, L.G. 1968. Manual of Histologic Staining Methods of the Armed Forces Institute of Pathology. $3^{\text {rd }}$ ed. McGraw Hill Book Co., New York, USA.

Mdegela, R.H., Yongolo, M.G.S., Minga, U.M. and Olsen, J.E. 2000. Molecular epidemiology of Salmonella Gallinarum in chickens in Tanzania. Avian Path. 29: 457- 463.

Merchant, I.A. and Packer, R.A. 1967. Veterinary Bacteriology and Virology $7^{\text {th }}$ ed. The lowa State University Press, Ames, lowa, USA. 211-306.

Msoffe, P.L.M., Minga, U.M., Mtambo, M.M.A., Gwakisa, P.S., Olsen, J.E. 2006. Differences in resistance to Salmonella Enterica serovar Gallinarum infection among indigenous local chicken ecotypes in Tanzania. Avian Path. 35: 270-276.

Office International Des Epizooties. 2004. OIE Manual Part-2: Pullorum Diseases and Fowl Typhoid In: OIE Manual Diagnostic Tests and Vaccines for Terrestrial Animals. $4^{\text {th }}$ edn. Paris, France.

Perez, C., Rivera, S., Pirela, A., Rincon, H., Mavarez, Y. and Roman, R. 2004. Isolation of Salmonella in poultry carcasses and evaluation of the effectiveness of different enrichment and selective media. Revist Cientiflic. Facult. Genti. V. Univers. del Zulia. 14: 177-185.

Robinson, H., Mdegela, M.G.S., Yongolo, U., Minga, M. and Johin, E. 2000. Molecular epidemiology of Salmonella Gallinarum in chickens in Tanzania. Avian Path. 29: 457-463.

Rybolt, M.L., Wills, R.W. and Bailey, R.H. 2005. Use of secondary enrichment for isolation of Salmonella from naturally contaminated environmental samples. Poult. Sci. 84: 992-997.

Sujatha, K., Dhanalakshmi, K. and Rao, A.S. 2003. Isolation and characterization of S. Gallinarum from chicken. Ind. Vet. J. 80: 473-474.

Tibaijuka, B., Molla, B., Hildebrandt, G. and Kleer, J. 2003. Occurrence of Salmonellae in retail raw chicken products in Ethiopia. Berliner. und Munchener. Tierar. Fiche. Wochen. 116: 55-58.

Truong, Q. and Tieuquang, A.N. 2003. Prevalence of Salmonella Gallinarum Pullorum infection in the Luong Phuong chickens reared in the household sector. Khoa.- Hoc.- Ky. -Thuat. -Thu. -Y.- Vet. -Sci.- and- Tech. 10: 15-19. 